\title{
Phytochemical Investigation and Screening for Inflammatory Bowel Disease Activity of Ethanolic Extract of Kariyat
}

\author{
Nilesh Balasaheb Chougule ${ }^{1,2}$, Sachin Annasaheb Nitave ${ }^{1,3}$, Kailasam Koumaravelou'
}

\section{Nilesh Balasaheb Chougule ${ }^{1,2}$, Sachin Anna- saheb Nitave ${ }^{1,3}$, Kailasam Koumaravelou ${ }^{1}$}

'Deptartment of Centre for Research and Development, PRIST University, Vallam, Thanjavur 613 403, Tamil Nadu, INDIA. ${ }^{2}$ Principal, Annasaheb Dange College of D. Pharmacy, Ashta, Sangli, Maharashtra, INDIA.

${ }^{3}$ Principal, Anil Alias Pintu Magdum College of D. Pharmacy, Dharnggutti, Kolhapur, Maharashtra, INDIA.

\section{Correspondence}

Mr Chougule Nilesh Balasaheb

Research scholar, Centre for Research and Development, PRIST University, Vallam, Thanjavur-613403, Tamil Nadu, INDIA.

Phone No: 08007076889

E-mail: nlshchougule@gmail.com

History

- Submission Date: 05-08-2017;

- Review completed: 31-08-2017;

- Accepted Date: 20-11-2017

DOI : 10.5530/pj.2018.3.99

Article Available online

http://www.phcogj.com/v10/i3

\section{Copyright}

(C) 2018 Phcog.Net. This is an openaccess article distributed under the terms of the Creative Commons Attribution 4.0 International license.

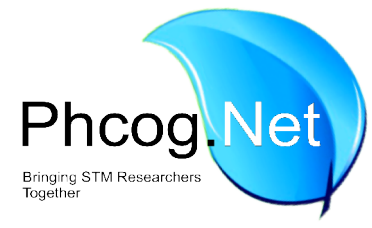

\begin{abstract}
Objectives: The present study investigates the protective effect of Kariyat against Indomethacin and Acetic Acid induced Inflammatory Bowel Disease in male wistar rats. Material Method: HPTLC and GC-MS investigations indicated presence of steroid, phenols, terpenoid, alkaloids, saponine, flavonoids. IBD was induced by administration of Indomethacin (7.5 mg/kg b.w. S.c.), Acetic Acid (4\% v/v). Two different models used to induce IBD named Indomethacin induces enter colitis and Acetic Acid induces enter colitis in case of Indomethacin induces enter colitis the compromises 5 groups $(n=6)$, normal, control, standard treated (Prednisolone $2 \mathrm{mg} / \mathrm{kg}$ p.o.), KEE treated (100 mg/kg b.w.), KEE treated (200 mg/kg b.w.) in case of Acetic Acid induces colitis the compromises 5 groups $(n=6)$, normal, control, standard treated (Prednisolone $2 \mathrm{mg} / \mathrm{kg}$ p.o.), KEE treated $(100 \mathrm{mg} / \mathrm{kg}$ b.w.), KEE treated (200 $\mathrm{mg} / \mathrm{kg}$ b.w.). After treatment of 7 days animals were sacrificed and colon was isolated for macroscopic and microscopic studies. Quantification of inflammation was done by using myeloperoxidase assay (MPO), Lactate dehydrogenase (LDH), Lipid peroxidase (LPO). Result: Evaluation based on macroscopic features showed significantly lower score values for drug treated and standard drug treated groups compared to the disease control groups. Histological examination of disease control group showed massive necrosis of the mucosa and sub mucosa. Drug treated group showed mild lesions, regeneration and inflammatory reaction. The Prednisolone treated group showed suppressed inflammatory reaction. The results observed from MPO, LDH and LPO assays showed significant improvement of disease with extract treated groups compared to disease control group. Histopathological examination of Kariyat treated group revealed less damage compared to Indomethacin and Acetic Acid Induced group. Conclusion: Kariyat have shown to be effective in Indomethacin and Acetic Acid induced colitis in rats, which has protected the animals against experimentally induced disease because of its antioxidant and anti-inflammatory activity.

Key words: Kariyat, Inflammatory bowel disease, Indomithacin, Acetic Acid, Myeloperoxidase assay (MPO), Lactate dehydrogenase (LDH), Lipid peroxidase (LPO), Myeloperoxidase assay (MPO), Lactate dehydrogenase (LDH), Lipid peroxidase (LPO)
\end{abstract}

\section{INTRODUCTION}

Inflammatory bowel disease (IBD) is a spectrum of chronic idiopathic inflammatory intestinal conditions. IBD causes significant gastrointestinal symptoms that include diarrhea, abdominal pain, bleeding, anemia and weight loss. IBD conventionally is divided into two major subtypes: Ulcerative colitis and Crohn's disease. Ulcerative colitis is characterized by confluent mucosal inflammation of the colon starting at the anal verge and extending proximally for a variable extent (e.g., proctitis, left-sided colitis, or pan colitis). Crohn's disease, by contrast, is characterized by trans mural inflammation of any part of the gastrointestinal tract but most commonly the area adjacent to the ileocecal valve. ${ }^{1}$ Both diseases increase the risk of adenocarcinoma of the colon in the affected area. ${ }^{2}$ Ulcerative colitis is most prevalent in North America, North Europe and Australia. The prevalence is roughly 10 times lower in southern and
Eastern Europe, Africa, Asia and South America. Some reports have indicated that disease is now seen with increased frequency in parts of Asia such as India, Bangladesh and Japan. ${ }^{3}$

Specific goals of pharmacotherapy in IBD include controlling acute exacerbations of the disease, maintaining remission, and treating specific complications such as fistulas. ${ }^{1}$ The main drugs used in the treatment of ulcerative colitis and crohn's disease are the amino salicylates and corticosteroids. ${ }^{4}$ Although many types of treatment have been proposed and clinically proven, additional therapeutic approaches are needed because many patients do not satisfactorily respond to the currently available options or show significant side effects due to their prolonged use. Therefore there is need to develop safe and effective alternative therapeutic agents for treatment of

Cite this article: Chougule NB, Nitve SA, Koumaravelou K. Phytochemical Investigation and Screening for Inflammatory Bowel Disease Activity of Ethanolic Extract of Kariyat. Pharmacog J. 2018;10(3):602-10. 
IBD. Considering oxidative stress as one of the factor in IBD, antioxidants could be expected to provide relief. ${ }^{5}$

Recent, albeit uncontrolled, trials have suggested that specific antioxidant treatment may be therapeutically effective in IBD. In corticosteroid resistant Crohn's disease (CD) a combination of superoxide dismutase and desferrioxamine was reportedly effective, ${ }^{6}$ while allopurinol has been used successfully in acute and chronic pouchitis. ${ }^{7}$ Antioxidants have been used successfully in experimental models of intestinal inflammation. ${ }^{8,9}$

Andrographis paniculata Nees (family Acanthaceae) is a popular medicinal herb used for treating infection, inflammation, cold, fever and diarrhea ${ }^{10}$ Andrographolide, a major bioactive compound of this plant, has been reported to inhibit the expression of inducible nitric oxide synthase ${ }^{11,12}$ and the production of neutrophil reactive oxygen species. It also exhibited cytotoxic activity against neoplastic cells ${ }^{13}$ and hepatoprotective activity against carbon tetrachloride, galactosamine and paracetamol intoxication AP extracts and their constituents have been shown to possess antiviral, anti-infective, anti-inflammation and immunostimulative activities. ${ }^{13}$ Although the detailed anti-inflammatory mechanism(s) of AP remain unclear, it was reported that andrographolide can protect against lipid peroxidation, ${ }^{14}$ and is involved in the anti-inflammatory mechanism of action. ${ }^{13}$ Keeping this in view, an attempt was made to search for the plants containing antioxidants for the evaluation of effectiveness in improving IBD. In our literature search, Andrographolides has been already proved for its anti-oxidant activity. Therefore it is been hypothesized that the hole plant of kariyat may be useful in treating IBD. However there are no scientific data regarding the utility of Kariyat Plant extract in the treatment of IBD. Thus has been selected for the present study.

\section{MATERIALS AND METHODS}

\section{Collection and Authentication of the Plant Material}

The aerial parts of plant of kariyat were collected from surrounding areas of Taluka Shirol, District Kolhapur, Maharashtra. The plant was washed with distilled water, dried at room temperature under shade. The sample was identified and authenticated by "Nikhil Analytical and Research Laboratory ( ISO 9001-2008 certified, Central Govt. Approved for Agmark), Sangli 416416, Maharashtra, India as well as by Head (UG and PG) Department of botany Dattajirao Kadam Arts, Science and Commerce College, Ichalkaranji, Taluka Hatkanangale, Dist. Kolhapur, Maharashtra, India.

\section{Preparation of Kariyat Ethanolic Extract (KEE)}

Kariyat was grinded to obtain coarse powder using an electric grinder. Powdered drug was extracted with ethanol in $25 \%$ concentration $(25 \mathrm{gm}$ of weighed Kariyat powder and $100 \mathrm{ml}$ of solvent at $60^{\circ} \mathrm{C}-80^{\circ} \mathrm{C}$ ), in a continuous hot extraction method using Soxhlet extractor. The extract was concentrated in a rotary flash evaporator (Hahn vapor, Hahn shin Scifintic Korea) and residue was dried in vacuum desiccators over anhydrous calcium chloride to yield ethanolic extract [KEE]. The percentage yield of ethanolic extract was calculated and it was $10.25 \%$. The extract was stored in refrigerator at $4{ }^{\circ} \mathrm{C}$ for further use (Table 2).

\section{Phytochemical Screening}

Preliminary qualitative Phytochemical analysis of the extract was carried out using various procedures ${ }^{15-18}$ to detect the presence of several phytochemical like Tannins, Terpenoids, Alkaloids, Flavonoids, Steroids and free Amino acid etc.

\section{HPTLC Analysis}

HPTLC analyses were carried out using CAMAG Linomat HPTLC instrument. Sample Preparation was done by taking weighed quantity of extract residue was dissolved in $1 \mathrm{ml}$ of chromatographic grade methanol which was used for sample application on pre-coated silica gel 60 F 254 aluminum sheets.

\section{Developing Solvent System}

A number of solvent systems were tried, for each extract for better resolution and maximum number of spots, but the satisfactory resolution was obtained in the solvent of tolnaftate: ethyl alcohol: formic acid:: 10:3:1.

\section{Sample Application}

Application of bands of each extract was carried out $(15 \mathrm{~mm}$ in length and $3 \mu$ in concentration) using spray technique. Samples were applied in duplicate on pre-coated silica gel 60 F254 aluminum sheets ( 5 x 10 $\mathrm{cm}$ ) with the help of Linomat 5 applicator attached to CAMAG HPTLC system, which was programmed through WIN CATS software.

\section{Development of Chromatogram}

After the application of sample, the chromatogram was developed in Twin trough glass chamber $10 \times 10 \mathrm{~cm}$ saturated with and solvent system in and tolnaftate: ethyl alcohol: formic acid: 10:3:1for aqueous extract.

\section{Detection of Spots}

$3 \mathrm{mg} / \mathrm{ml}$ concentration of extracts were prepared in methanol of chromatographic grade and then filtered by whatman filter paper No. 1. Prepared samples of different extracts were applied on TLC aluminum sheets silica gel 60 F 254 (Merck) $07 \mu \mathrm{l}$ each with band length of $8 \mathrm{~mm}$, sample applicator set at a speed of $150 \mathrm{ml} / \mathrm{sec}$.

\section{GC-MS analysis}

GC-MS analysis was carried out on a TURBOMASS 2017. The column used was capillary column measuring $30 \mathrm{~m} \times 0.25 \mathrm{~mm}$ with a film thickness of $0.25 \mathrm{~mm}$ composed of $95 \%$ Dimethyl polysiloxane. Sample injection volume of 1 micro litter was utilized and inlet temperature was maintained as $250^{\circ} \mathrm{C}$. The oven temperature was programmed initially at $110^{\circ} \mathrm{C}$ for $4 \mathrm{~min}$, then an increase to $240^{\circ} \mathrm{C}$. And then programmed to increase to $280^{\circ} \mathrm{C}$ at a rate of $20^{\circ} \mathrm{C}$ ending with a $5 \mathrm{~min}$. Total run time was $90 \mathrm{~min}$. The MS transfer line was maintained at a temperature of $200^{\circ} \mathrm{c}$. The source temperature was maintained at $180^{\circ} \mathrm{c}$. GCMS was analyzed using electron impact ionization at $70 \mathrm{eV}$ and data was evaluated using total ion count (TIC) for compound identification and quantification. The spectrums of the components were compared with the database of spectrum of known components stored in the GC-MS library.

\section{Animals Care and Handling}

The experiment was approved by the institutional animal ethics committee of S. E. T. College of Pharmacy, S. R. Nagar Dharwad. The experiment was carried out on Albino rats of wistar strain and Swiss albino mice of both sexes weigh around $200 \mathrm{~g}$ and $25 \mathrm{~g}$ respectively. Animals were procured from Venkateshwara Enterprises, Bangalore and were housed in the animal house. The animals were acclimatized to the standard laboratory conditions in cross ventilated animal house at temperature $25 \pm 2{ }^{\circ} \mathrm{C}$ relative humidity 44 to $56 \%$ and light and dark cycles of $12: 12 \mathrm{~h}$, fed with standard pallet diet and water ad libitum during experiment. The animals were kept in polypropylene cages in groups. The research was conducted in accordance with the ethical rules on animal experimentation. 


\section{Screening for Inflammatory Bowel Disease}

\section{Indomethacin-induced enter colitis in rats}

The male wistar albino rats (200-250 gm) were selected and randomized into five groups of six animals in each group. Group 1 served as Normal or untreated animals, group 2 was positive control (induced) animals receive only Indomethacin $(7.5 \mathrm{mg} / \mathrm{kg})$ s.c group 3 was treated group with lower dose received Indomethacin $(7.5 \mathrm{mg} / \mathrm{kg})$ s.c along with TGE, group 4 was treated group with higher dose received Indomethacin $(7.5 \mathrm{mg} / \mathrm{kg})$ s.c along with KEE and group5 standard group received indomethacin $(7.5 \mathrm{mg} / \mathrm{kg})$ s.c along with Prednisolone $(2 \mathrm{mg} / \mathrm{kg}$ p.o). Animals pretreated with Kariyat extract for 7 days will be administered Indomethacin $(7.5 \mathrm{mg} / \mathrm{kg}$, s.c. $)$ on $8^{\text {th }}$ and $9^{\text {th }}$ day of treatment. Extract will be administered till $11^{\text {th }}$ day. On the $11^{\text {th }}$ day the animals will be sacrificed by cervical dislocation and dissected. Ileum and colon will be taken out to assess inflammation, based on physical parameters, macroscopy and microscopic features. Quantification of inflammation would be done using biochemical assay (MPO, lipid peroxides, GSH). ${ }^{16,18,19}$

\section{Acetic acid-induced Colitis in rats}

The male wistar albino rats (200-250 gm) were selected and randomized into five groups of six animals in each group. Group 1 served as Normal or untreated animals, group 2 was positive control (induced) animals receive $2 \mathrm{ml}$ of $4 \%(\mathrm{v} / \mathrm{v})$ acetic acid. group 3 was treated group with lower dose received $2 \mathrm{ml}$ of $4 \%(\mathrm{v} / \mathrm{v})$ acetic acid along with TGE, group 4 was treated group with higher dose received $2 \mathrm{ml}$ of $4 \%(\mathrm{v} / \mathrm{v})$ acetic acid along with KEE and group5 standard group received $2 \mathrm{ml}$ of $4 \%(\mathrm{v} / \mathrm{v})$ acetic acid along with Prednisolone ( $2 \mathrm{mg} / \mathrm{kg}$ p.o). Animals will be treated with Kariyat extract for 7 days. On the $8^{\text {th }}$ day, overnight fasted animals will be anaesthetized using pentobarbitone sodium and $2 \mathrm{ml}$ of $4 \%$ acetic acid solution will be instilled into rectum. After $48 \mathrm{~h}$ animals will be sacrificed by cervical dislocation and dissected to remove colon. Waste material will be removed from colon and it will be flushed with saline gently. Inflammation will be assessed based on physical parameters, macroscopy and microscopic features. Quantification of inflammation would be done using biochemical assay (MPO and lipid peroxides). ${ }^{16,18,19}$

\section{Anti-oxidant activity of bark extract of Kariyat}

The bark extract of Kariyat will be taken and subjected to anti-oxidant screening by chemical methods at different concentration. The free radical scavenging property of extracts will be analyzed by 1, 2-diphenyl 1-phenyl hydrazil. Anti-oxidants status of all scavenge those free radicals at different concentration will be analysed. ${ }^{20}$

\section{Evaluation of the disease}

The disease induced in experimental animals was evaluated based on its macroscopic and microscopic characteristics. Evaluation pattern for macroscopic characteristics, given by ${ }^{20}$ was used after some modifications. The inflammation was measured quantitatively using Myeloperoxidase assay.

\section{Evaluation Based on Macroscopic Characters}

\section{Scoring for rat colon. ${ }^{21}$}

For each animal, the distal $10 \mathrm{~cm}$ portion of the colon was removed and cut longitudinally, and slightly cleaned in physiological saline to remove faecal residues. Pieces of rat ileum and colon (10 cm long each) were scored for macroscopic features using following scoring pattern.

\section{Percentage area affected of rat colon: ${ }^{21}$}

Rat colon (5 cm long) was scored for macroscopic features using following scoring pattern. Table 1
Score for an individual rat was calculated as the combined score of ileum, colon, and caecum.

\section{Evaluation based on microscopic (histological) characters}

The colon from each animal was removed after sacrificing the animal and was collected and preserved in $10 \%$ formalin solution. The samples were submitted to Jeevan Regional Diagnostic Health Care and Research Centre Pvt Ltd. (Belgaum, India) for histological examination.

\section{Myeloperoxidase assay for quantification of inflammation}

Pieces of inflamed tissues (colon- $4 \mathrm{~cm}$ ) were taken. The tissue was then rinsed with ice-cold saline, blotted dry, weighed and excised. Minced tissue was homogenized in 10 volumes of ice-cold potassium phosphate buffer ( $\mathrm{pH} 7.4$ ), using Remi tissue homogenizer (RQ-127A). The homogenate was centrifuged at $3500 \mathrm{rpm}$ for $30 \mathrm{~min}$ at $4^{\circ} \mathrm{C}$ (Remi centrifuge C23). The supernatant was discarded. $10 \mathrm{ml}$ of ice- cold $50 \mathrm{mM}$ potassium phosphate buffer ( $\mathrm{pH} 6.0$ ), containing $0.5 \%$ hexadecyl trim ethyl ammonium bromide (HETAB) and 10mM EDTA was then added to the pellet. It was then subjected to one cycle of freezing and thawing and brief period (15 s) of sonication. After sonication solution was centrifuged at 15,000 rpm for $20 \mathrm{~min}$. (Remi centrifuge, R24). Myeloperoxidase (MPO) activity was measured spectrophotometrically as follows. $0.1 \mathrm{ml}$ of supernatant was combined with $2.9 \mathrm{ml}$ of $50 \mathrm{mM}$ phosphate buffer containing $0.167 \mathrm{mg} / \mathrm{ml} \mathrm{O}$-dianisidine hydrochloride and $0.0005 \% \mathrm{H} 2 \mathrm{O} 2$. The change in absorbance was measured spectrophotometrically (Shimadzu UV 1 60A UV-VIS spectrophotometer), at 460 $\mathrm{nm}$. One unit of MPO activity is defined as the change in absorbance per minute by 1.0 at room temperature, in the final reaction.

Calculation of MPO activity

\section{Measurement of colonic lipid peroxides concentration}

Lipid peroxidation, an indicator of mucosal injury induced by reactive oxygen species was measured as thiobarbituric acid reactive substance. The amount of colonic lipid peroxides was measured by the thiobarbituric acid assay (TBA). Briefly, $0.5 \mathrm{ml}$ of colonic tissue homogenates prepared were reacted with $2 \mathrm{ml}$ of TBA reagent containing $0.375 \%$ TBA, $15 \%$ trichloroacetic acid and $0.25 \mathrm{~N} \mathrm{HCl}$. Samples were boiled for 15 min, cooled and centrifuged. Absorbance of the supernatants was spectrophotometrically measured at $532 \mathrm{~nm}$. TBARS concentrations were calculated by the use of 1,3,3,3 tetra-ethoxypropane as a standard. The results were expressed as $\mu \mathrm{mol} / \mathrm{g}$ wet tissue weight.

\section{Statistical Analysis}

All data was expressed as mean \pm standard error of the mean (S.E.M.) of 6 rats per experimental group. Statistical analysis was performed using Graph pad prism 5.0 statistical software. Parametric one way analysis of variance (ANOVA) followed by Tukey's posttest. The minimal level of significance was identified at $P<0$.

\section{RESULTS AND DISCUSSION}

Extraction of Kariyat was carried out by continuous hot extraction method by Soxhlet apparatus using ethyl alcohol and temperature of apparatus was kept around $60-70^{\circ} \mathrm{C}$. Thus obtained ethanolic extract was further concentrated by rotary evaporator to get grayish brown colored slurry with specific teak wood smell and around $8.13 \%$ yield was obtained. (Table 1)

Extracts was subjected for preliminary qualitative analysis to detect the presence of several phytochemicals The results indicated that the extract showing positive tests for alkaloids, flavonoids, steroids, saponins, cardiac glycosides, tannins, terpenoids, and free amino acid and confirmed the presence of aleurone grains, alkaloids, amino acids, carbohydrate, fat and fixed oils, flavonoids, glycoside, inulin, mucilage, tannin, proteins, 
steroids and triterpenoids. These results were further confirmed by spectral and chromatographic studies.

HPTLC profiling of ethanolic extract showed the presence of 9 constituents at different $\mathrm{Rf}$ values at $254 \mathrm{~nm}$. The developed TLC plates and HPTLC chromatograms are given in Figure 1. Peak 1, 2, 3, 4, 5, 6, 7, 8 and 9 got Rf value of $0.36,0.43,0.47,0.56,0.61,0.71,0.76,0.82$ and 0.87 respectively. KEE showed the presence of andrographolide and which was confirmed with retardation factor Rf 0.6. The KEE showed the presence of andrographolide in the respective $\mathrm{Rf}$ region, which matched very well with that of standard andrographolide (Figure 1).

\section{GC-MS analysis}

GC-MS analysis Kariyat is presented in Figure 2 and found major fractions at RT 22.275 with \% area of 56.66. Interpretation these fractions were done by confirming data bank of National Institute of Standards and Technique by comparing the molecular weight and molecular formula. The spectrum showed the presence of 1,2,3,5-Cyclohexanetetrol and various analogs of Quinic acid in ethanolic extract of Kariyat (Figure)

\section{Indomethacin-induced Enter colitis in rats}

Two days treatment with Indomethacin $(7.5 \mathrm{mg} / \mathrm{kg}$, s.c.), produced severe inflammation in rat intestine. The middle portion of the small intestine i.e. jejunum and proximal ileum showed more inflammation compared to proximal portion of the small intestine. Caecum was the most severely affected part, showing haemorrhagic spots. The ileum showed many lesions, which were Tran's mural. In between there were skip areas of normal tissue. In some animals the large intestine was found to be affected with haemorrhagic lesions. Evaluation based on macroscopic features showed significantly $(\mathrm{P}<0.001)$ lower score values for drug treated and standard treated group compared to the positive control group. Score values of the drug treated group were comparable with the scores obtained in standard treated group (Table 3).

Table represents significant reduction in macroscopic score value compare to Indomethacin alone. Each value represents mean of macroscopic scores \pm S.E.M. $(n=6)$. Significant in macroscopic score values according to one-way ANOVA followed by Tukey's post-test, $\mathrm{P}$ values of ${ }^{*}<0.05$

Table 1: Percentage area affected of rat colon

\begin{tabular}{cc}
\hline Score & Percentage area affected \\
\hline 0 & 0 \\
1 & $1-15$ \\
2 & $5-10$ \\
3 & $10-25$ \\
4 & $25-50$ \\
5 & $50-75$ \\
6 & $75-1000$ \\
\hline
\end{tabular}

Table 2: Results of \% Yield of ethanolic extract of Kariyat

\begin{tabular}{cccc}
\hline Batch & $\begin{array}{c}\text { Initial weight of powder drug in } \\
\text { grams }\end{array}$ & $\begin{array}{c}\text { Weight of } \\
\text { extract }\end{array}$ & $\begin{array}{c}\% \\
\text { yield }\end{array}$ \\
\hline I & 25.4 & 1.87 & 7.37 \\
II & 26.1 & 2.21 & 8.47 \\
III & 1235.3 & 2.16 & 8.55 \\
& & Average & 8.13 \\
\hline
\end{tabular}

were considered statistically significant. ${ }^{\mathrm{x}} \mathrm{P}<0.001$ compare to Indomethacin alone.

The myeloperoxidase assay showed significant increase in MPO activity of positive control group compared to normal untreated group. The drug treated and standard treated group showed significant $(\mathrm{P}<0.01, \mathrm{P}<0.001)$ reduction in MPO activity compared to the positive control group. MPO activity of the drug treated group was comparable with the standard treated group (Table 5 and Figure 3). The lactate dehydrogenase (LDH) assay showed significant $(\mathrm{P}<0.001)$ increase in LDH activity of positive control group compared to normal untreated group. The drug treated and standard treated group showed significant $(\mathrm{P}<0.01, \mathrm{P}<0.001)$ reduction in LDH activity compared to the positive control group. LDH activity of the drug treated group was comparable with the standard treated group (Table 4 and Figure 4 ).

The Lipid peroxidase (LPO) assay showed significant $(\mathrm{P}<0.001)$ increase in LPO activity of positive control group compared to normal untreated group. The drug treated and standard treated group showed significant $(\mathrm{P}<0.01, \mathrm{P}<0.001)$ reduction in LPO activity compared to the positive control group. LPO activity of the drug treated group was comparable with the standard treated group (Table 5, 4 and Figure5).

Histological examination of positive control group showed advanced lesions as necrosis of even payer's patches and fragmentation of nuclei. The drug treated group showed reduced intensity of lesions without any evidence of necrosis, regeneration or inflammatory reaction. Standard treatment showed suppressed inflammatory reaction.

\section{Acetic acid-induced colitis in rats}

Intra-rectal instillation of acetic acid caused inflammatory reaction in the colon. The inflammation covered rectum and distal colon portion. The visible changes included severe epithelial necrosis and ulcerated mucosa. Drug treated and standard treated group showed significantly $(\mathrm{P}<0.001)$ lower score values of macroscopic evaluation as compared to positive control group and values obtained for the drug treated group were comparable with the standard treated group (Table 5).

Table represents significant reduction in macroscopic score value compare to acetic acid alone. Each value represents mean of macroscopic scores \pm S.E.M. $(n=6)$. Significant in macroscopic score values according to one-way ANOVA followed by Tukey's post-test, $\mathrm{P}$ values of $<0.05$ were considered statistically significant. $\mathrm{cP}<0.001$ compare to acetic acid alone (Figure 7).

The myeloperoxidase assay showed significant $(\mathrm{P}<0.001)$ increase in MPO activity of positive control group compared to normal group. The drug treated and standard treated groups showed significant $(\mathrm{P}<0.01$, $\mathrm{P}<0.001)$ decrease in MPO activity compared to positive control group

Table 3: Effect of Kariyat extract on macroscopic features in Indomethacin-induced Enterocolitis in rats.

\begin{tabular}{lc}
\multicolumn{1}{c}{ Treatment groups } & $\begin{array}{c}\text { Mean of macroscopic scores } \\
\pm \text { S.E.M }\end{array}$ \\
\hline $\begin{array}{l}\text { Normal or untreated animals. } \\
\text { Control animals receive only indomethacin } \\
(7.5 \mathrm{mg} / \mathrm{kg}) \text { s.c. }\end{array}$ & 0 \\
$\begin{array}{l}\text { Animals treated with indomethacin }(7.5 \mathrm{mg} / \\
\mathrm{kg}) \mathrm{s.c}+\text { lower dose. (KEE) }\end{array}$ & $4.46 \pm 0.56$ \\
$\begin{array}{l}\text { Animals treated with indomethacin }(7.5 \mathrm{mg} / \\
\mathrm{kg}) \text { subcutaneous + higher dose. }(\mathrm{KEE})\end{array}$ & $3.53 \pm 0.58^{*}$ \\
$\begin{array}{l}\text { Animals, which will receive Prednisolone } \\
(2 \mathrm{mg} / \mathrm{kg} \text { p.o) and indomethacin }(7.5 \mathrm{mg} / \mathrm{kg}) .\end{array}$ & $1.45 \pm 0.22^{\mathrm{x}}$ \\
\hline
\end{tabular}




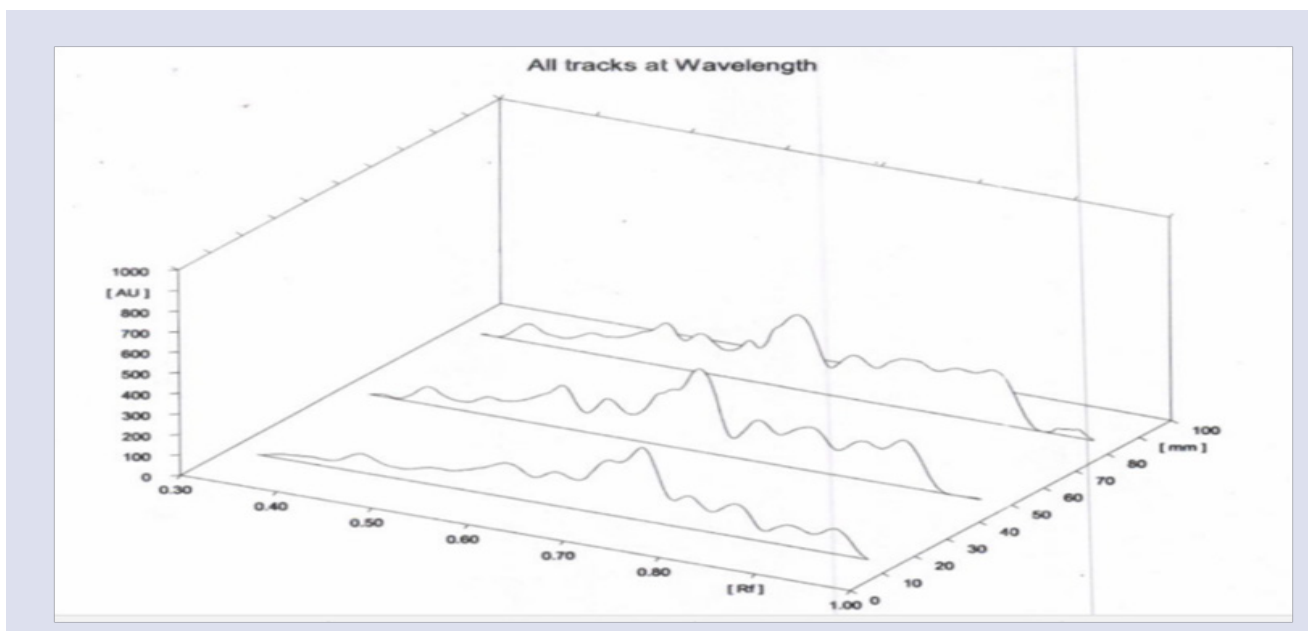

Figure 1: HPTLC Chromatograms of Ethanolic Extract of Kariyat.

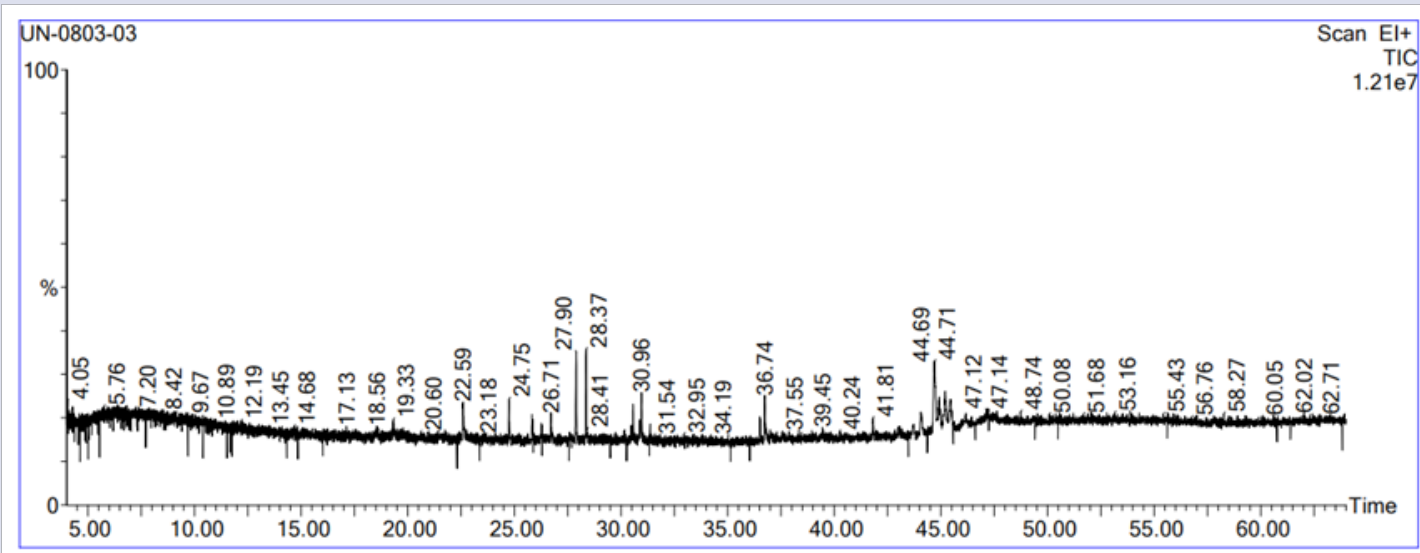

Figure 2: GC-MS analysis ethanolic extract of Kariyat.



Figure 3: Effect of Kariyat extract on MPO activity in Indomethacininduced Enter colitis in rats.

(Table 6 and Figure 8). The lactate dehydrogenase (LDH) assay showed significant $(\mathrm{P}<0.001)$ increase in $\mathrm{LDH}$ activity of positive control group compared to normal group. The drug treated and standard treated groups showed significant $(\mathrm{P}<0.01, \mathrm{P}<0.001)$ decrease in $\mathrm{LDH}$ activity compared to positive control group (Table 6 and Figure 9).

The lipid peroxidase $(\mathrm{LPO})$ assay showed significant $(\mathrm{P}<0.001)$ increase in LPO activity of control group compared to normal group. The



Figure 4: Effect of Kariyat extract on LDH activity in Indomethacininduced Enter colitis in rats.

drug treated and standard treated groups showed significant $(\mathrm{P}<0.01$, $\mathrm{P}<0.001)$ decrease in LPO activity compared to positive control group (Table 6and Figure 10).

Histological examination of control group showed massive necrosis of the mucosa and sub mucosa. Payers patches appeared distorted with karyohexis and karyolysis. Drug treated group showed mild lesions, 


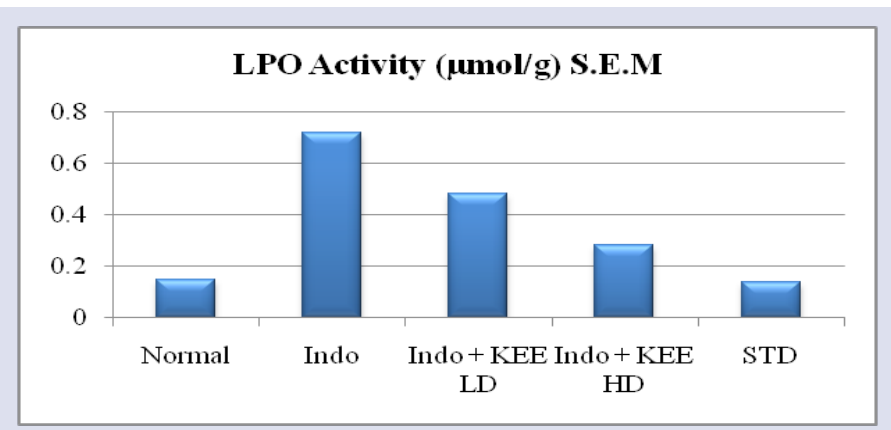

Figure 5: Effect of Kariyat extract on LPO activity in Indomethacininduced Enter colitis in rats.
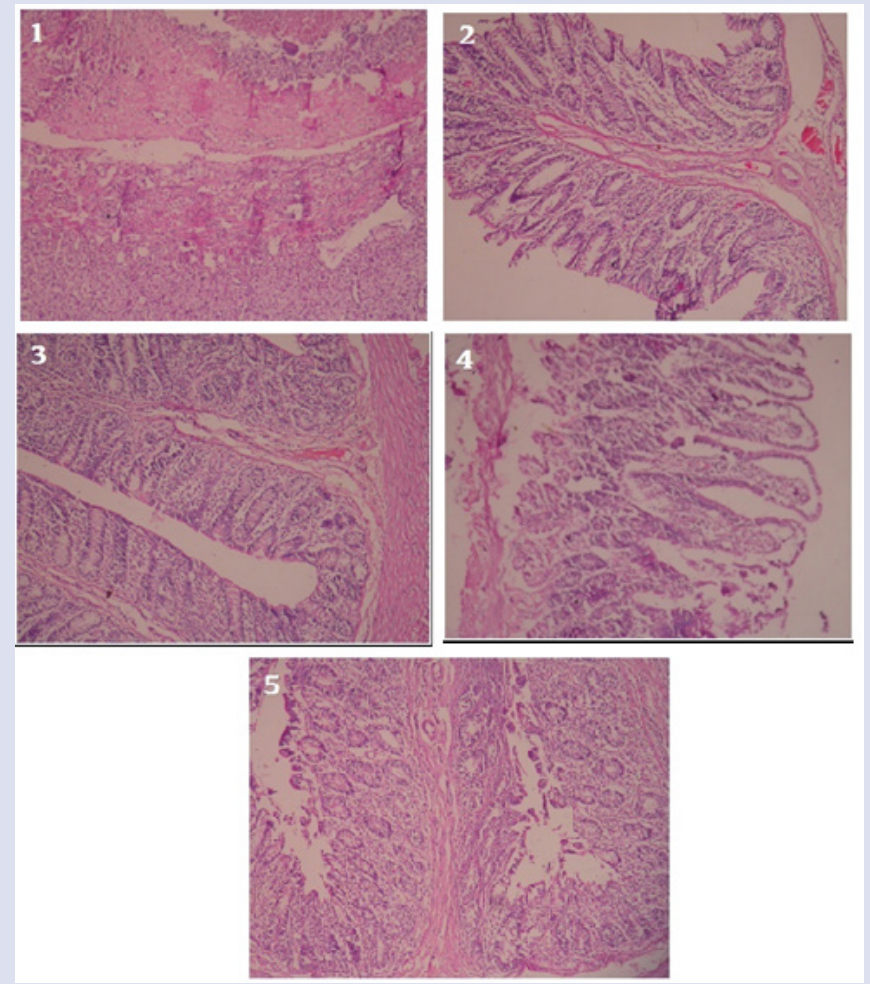

Figure 6: Histopathological Images of normal and treated enter colon.

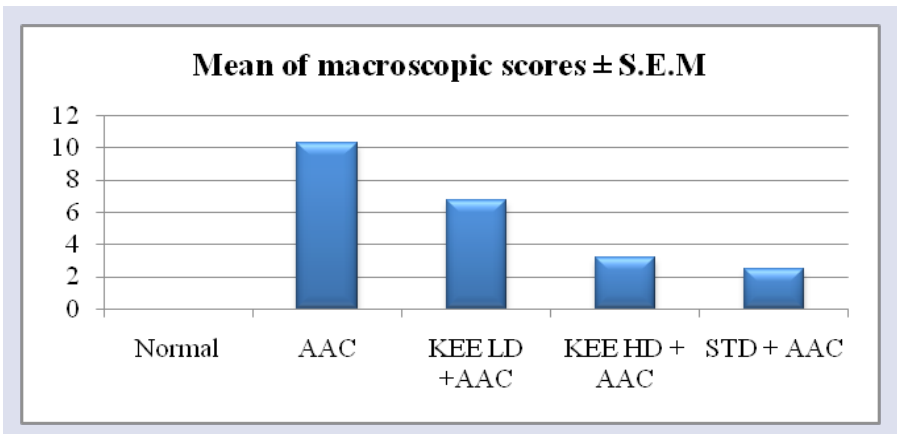

Figure 7: Effect of Kariyat ethanolic extract macroscopic features in acetic acid induced colitis in rats.

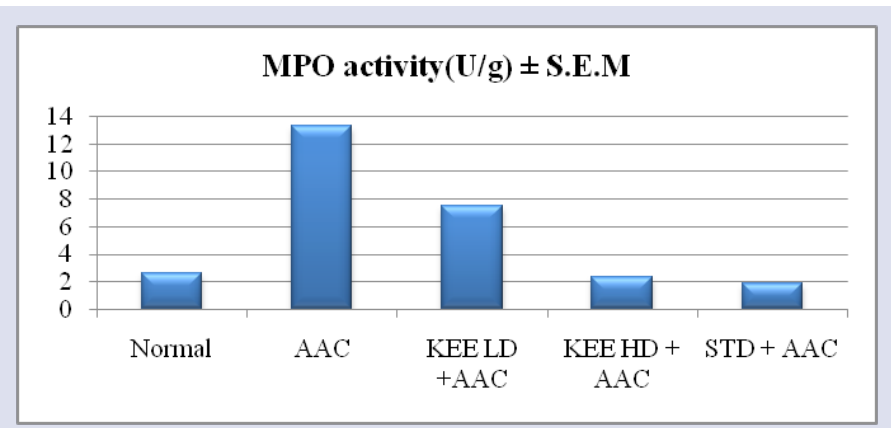

Figure 8: Effect of Kariyat extract on MPO activity in acetic acid-induced enterocolitis in rats.

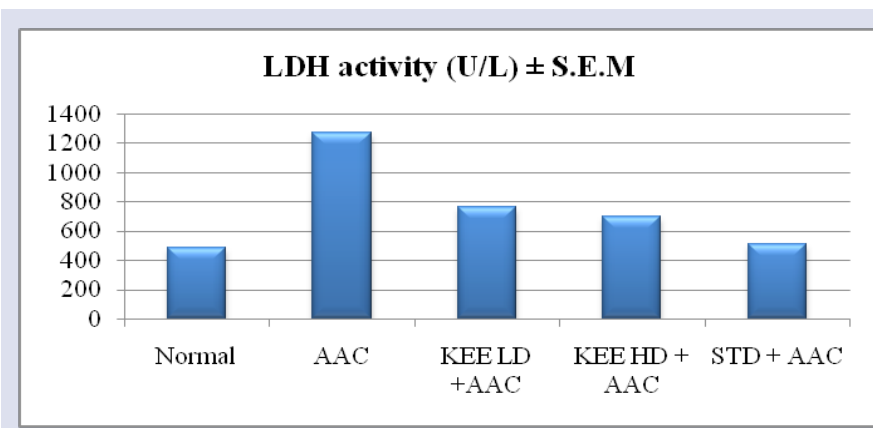

Figure 9: Effect of Kariyat extract on LDH activity in acetic acid-induced enter colitis in rats.

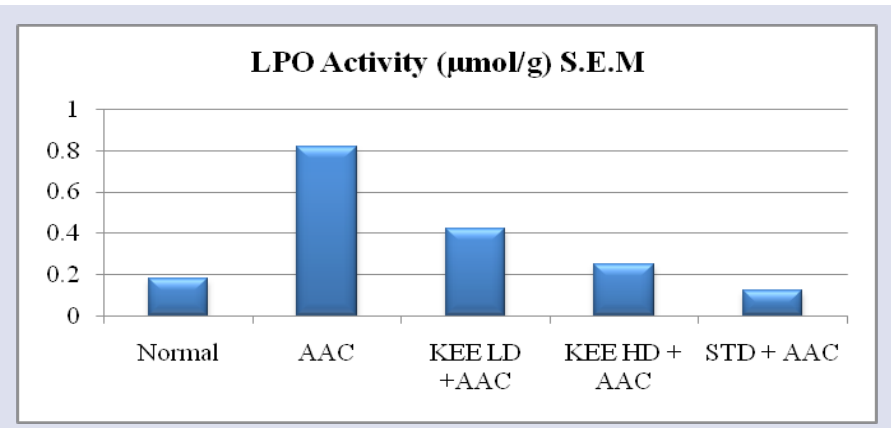

Figure 10: Effect of Kariyat extract on LPO activity in acetic -induced enter colitis in rats.

regeneration and inflammatory reaction. The standard treated group showed suppressed inflammatory reaction. (Figure 11 and 6).

Prostaglandins inhibition was studies by inhibition of Castor oil induced diarrhea in rats. Administration of Castrol induced diarrhea around 9 fecal drops with total weight of $5.5 \mathrm{~g}$ in four hours. This was reduced in both test and standard groups. Indicating KEE produces action by inhibiting the synthesis of prostaglandins (see Table 7).

\section{DISCUSSION}

The models used for study of IBD are acetic acid induced ulcerative colitis and indomethacin induced enter colitis. Intrarectal instillation of acetic acid in rats affected only the distal colon portion. The inflammation was not trans mural. Massive necrosis of mucosal and sub mucosal layers was observed. This model shares many of the histologic features of ulcerative colitis in human beings including mucosal edema, neutrophil infiltration of the mucosa and sub mucosal ulceration. ${ }^{22}$ The mechanism by which 
Table 4: Effect of Kariyat extract on MPO, LDH and LPO activity in Indomethacin-induced Enterocolitis.

\begin{tabular}{|c|c|c|c|c|}
\hline Groups & Treatment Groups & $\begin{array}{l}\text { MPO activity } \\
(\mathrm{U} / \mathrm{g}) \pm \text { S.E.M }\end{array}$ & $\begin{array}{l}\text { LDH activity } \\
\text { (U/L) } \pm \text { S.E.M }\end{array}$ & $\begin{array}{l}\text { LPO Activity } \\
(\mu \mathrm{mol} / \mathrm{g}) \text { S.E.M }\end{array}$ \\
\hline I & Normal or untreated animals. & $2.17 \pm 0.31$ & $522.67 \pm 6.38$ & $0.15 \pm 0.04$ \\
\hline II & $\begin{array}{l}\text { Control animals receive only Indomethacin } \\
(7.5 \mathrm{mg} / \mathrm{kg}) \text { s.c. }\end{array}$ & $15.67 \pm 0.51$ & $1234.67 \pm 60.68$ & $0.72 \pm 0.06$ \\
\hline III & $\begin{array}{l}\text { Animals treated with Indomethacin }(7.5 \mathrm{mg} / \\
\mathrm{kg}) \text { s.c. + lower dose (KEE) }\end{array}$ & $9.23 \pm 0.84^{\mathrm{B}}$ & $929.17 \pm 75^{b}$ & $0.48 \pm 0.09^{c}$ \\
\hline IV & $\begin{array}{l}\text { Animals treated with Indomethacin }(7.5 \mathrm{mg} / \\
\mathrm{kg}) \text { s.c. }+ \text { higher dose(KEE) }\end{array}$ & $4.50 \pm 1.13^{\mathrm{C}}$ & $805.0 \pm 61^{\mathrm{a}}$ & $0.28 \pm 0.08^{\mathrm{a}}$ \\
\hline V & $\begin{array}{l}\text { Animal treated group, which will receive } \\
\text { Prednisolone }(2 \mathrm{mg} / \mathrm{kg} \text { p.o }) \text { and indomethacin } \\
7.5 \mathrm{mg} / \mathrm{kg}) \text { s.c. }\end{array}$ & $1.97 \pm 0.21^{\mathrm{C}}$ & $578.67 \pm 100^{\mathrm{b}}$ & $0.14 \pm 0.02^{\mathrm{b}}$ \\
\hline
\end{tabular}

Each value represents mean of MPO activity (U/g), LDH (U/L), LPO $(\mu \mathrm{mol} / \mathrm{g}) \pm$ S.E.M. $(\mathrm{n}=6)$. (One-way ANOVA followed by Tukey's post-test)
a. Significant decrease in MPO, $\mathrm{LDH}, \mathrm{LPO}$ activity $\mathrm{P}<0.01$ w.r.t positive control group
b. $\quad$ Significant decrease in MPO, LDH, LPO activity $\mathrm{P}<0.001$ w.r.t positive control group
c. Significant increase in MPO, LDH, LPO activity $\mathrm{P}<0.001$ w.r.t normal group

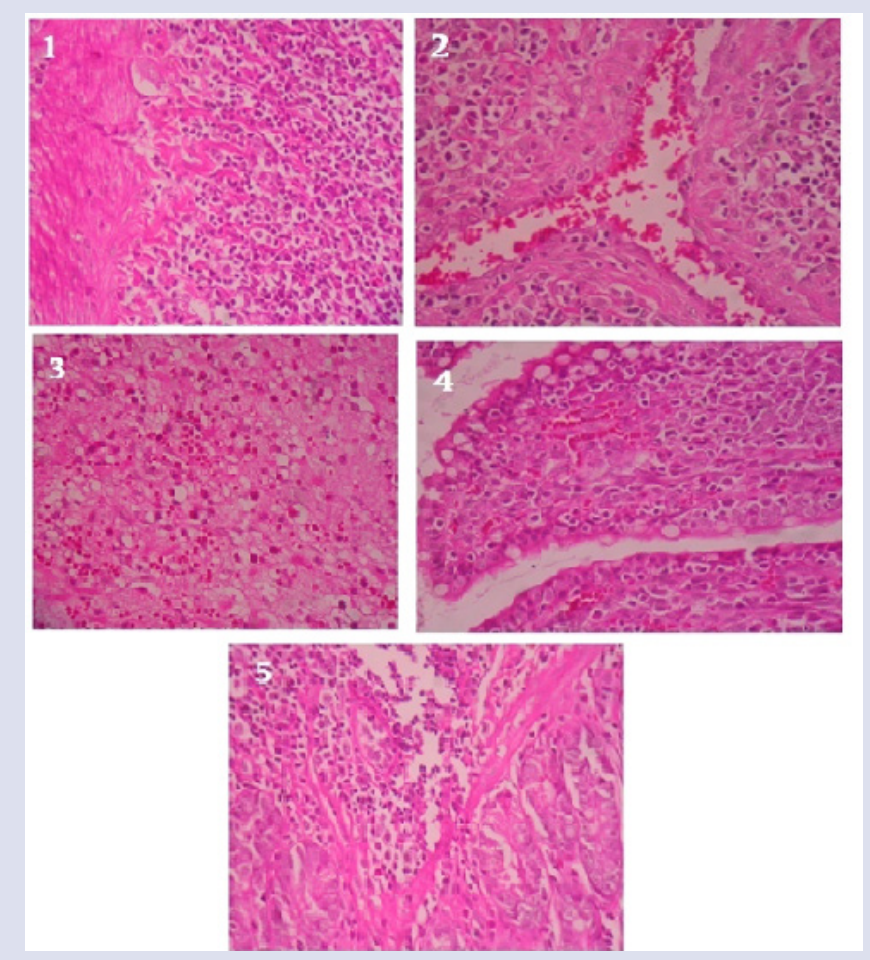

Figure 11:Histopathological Images of normal and treated colon.

acetic acid produces inflammation appears to involve the entry of the protonated form of the acid into epithelium, where it dissociates to liberate protons causing intracellular acidification that most likely accounts for the epithelial injury observed. The inflammatory response initiated by acetic acid includes activation of cyclooxygenase and lipooxygenase
Table 5: Effect of Kariyat ethanolic extract macroscopic features in acetic acid induced colitis in rats

\begin{tabular}{lc}
\hline \multicolumn{1}{c}{ Treatment groups } & $\begin{array}{c}\text { Mean of macroscopic } \\
\text { scores } \pm \text { S.E.M }\end{array}$ \\
\hline $\begin{array}{l}\text { Normal } \\
\text { Positive control- Acetic acid in saline alone } 2 \mathrm{ml} \\
(4 \%, \mathrm{v} / \mathrm{v}) \text { (once, intra-rectally) }\end{array}$ & 0 \\
Ethanolic extract of Kariyat + Acetic acid in saline & $10.27 \pm 0.40$ \\
$2 \mathrm{ml}(4 \%, \mathrm{v} / \mathrm{v})$ (once, intra-rectally) [KEE] & $6.72 \pm 0.80^{*}$ \\
Ethanolic extract of Kariyat + Acetic acid in saline & \\
$2 \mathrm{ml}(4 \%, \mathrm{v} / \mathrm{v})($ once, intra-rectally) [KEE] & $3.21 \pm 0.48^{\mathrm{x}}$ \\
Standard $(500 \mathrm{mg} / \mathrm{kg}$, p.o. $)+$ Acetic acid in saline & \\
$2 \mathrm{ml}(4 \%, \mathrm{v} / \mathrm{v})($ once, intra-rectally) & $2.48 \pm 0.17^{\mathrm{x}}$ \\
\hline
\end{tabular}

pathways and generation of inflammatory mediators like prostaglandins and leukotrienes. Excess production of reactive oxygen metabolites e.g superoxide, hydroxyl radical, hydrogen peroxide, hypochlorous acid and oxidant derivatives such as $\mathrm{N}$-chloramines are detected in inflamed mucosa and may be pathogenic in IBD. Also, there is an increase in proinflammatory cytokine TNF - $\alpha$ production in colonic mucosa after acetic acid instillation.

Indomethacin, a non-selective COX inhibitor produces enter colitis in rats on sub cutaneous administration which is characterized by linear ulceration, thickening and trans mural inflammation. The mechanism of indomethacin induced enter colitis have not been fully illustrated, but previous reports suggests that, inhibition of protective prostaglandins PGE1, PGE2 and prostacyclin (PG12) may be one of the mechanism by which indomethacin induces injury. In addition, bacteria and bacterial products, biliary secretion and food intake have been demonstrated to be important for the development of the intestinal lesions. 
Table 6: Effect of ethanolic extract of Kariyat on MPO, LDH and LPO activity in acetic acid-induced colitis in rats.

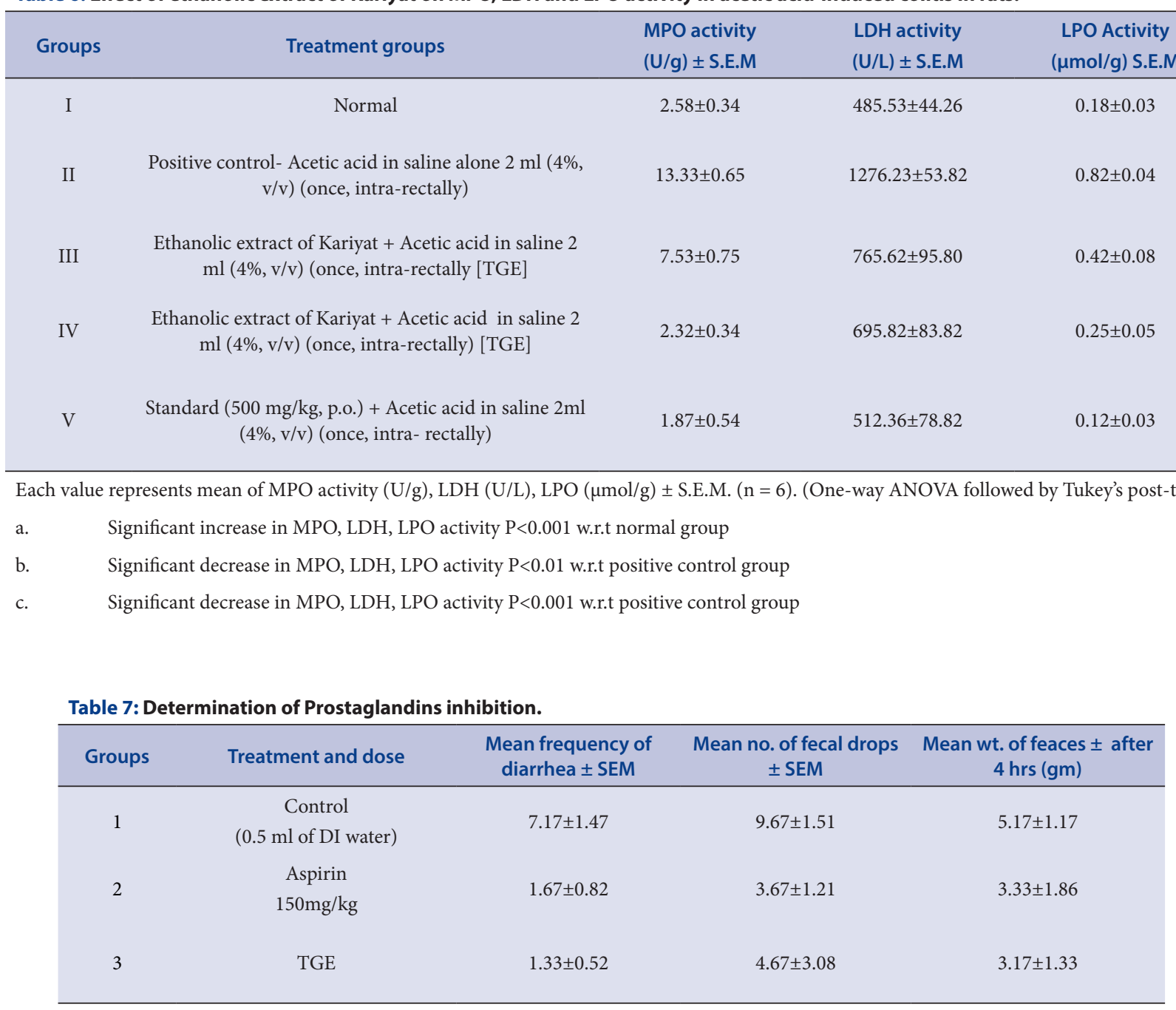

The treatment with the extract of Kariyat has shown a decrease in the macroscopic scores for the inflammation. Since the intestine is in a constant state of controlled inflammation, thus amplification of the inflammatory response activates infiltration of inflammatory cells that triggers pathological responses and symptoms of IBD. ${ }^{23}$ Our study showed that acetic acid raised the levels of colonic MPO, indicating infiltration of neutrophils and perturbation of the inflammatory system. ${ }^{24}$ This fact is documented in both animalmodels, ${ }^{17}$ and patients with IBD. ${ }^{25}$ Kariyat extract ameliorated neutrophil infiltration as evidenced by suppression of colon MPO and improvement of histological features.

Histopathology examination of drug treated group revealed less damage compared to control group. A significant decrease in MPO activity was also observed. All these observations support the findings that the extract of Kariyat was able to offer significant protection in both the models studied. Acetic acid-induced colitis and indomethacin-induced enter colitis simulate two different disease conditions, which are ulcerative colitis and Crohn's disease respectively. On this basis we can say that the constituents extract under study may be useful in treating UC as well as CD in humans. The prednisolone treatment has shown significant protection in both the animal models under our study. Ethanolic extract of Kariyat was found comparable with standard drug. The role of oxygen-derived free radicals, such as hydroxyl radical and superoxide radical, in the inflammatory process is well known. It is also generally assumed that most of the antioxidants possess anti-inflammatory effect. Ethanolic extract of Kariyat. May account for the observed anti-inflammatory properties.

\section{CONCLUSION}

The extract of Kariyat has potent protection against inflammatory bowel activity in both indomethacin induced enter colitis and acetic acid induced ulcerative colitis. Collectively, these findings indicate that the anti-oxidant effect of fraction may be an important contributor to its anti-inflammatory activity in IBD. This present investigation has also opened avenues for treatment of IBD from the title plant.

\section{REFERENCES}

1. Sellin JH, Pasricha PJ. Pharmacotherapy of inflammatory bowel disease. In: Brunton LL, Lazo JS, Parker KL, editors. Goodman and Gilman's The Pharmacological Basis of Therapeutics. 11 th Ed. New York (NY): McGraw Hill. 2006:100919.

2. Dudzinski DM, Serhan. Pharmacology of eicosanoids. In: Golan DE, Tashiian $\mathrm{AH}$, Armstrong EJ, Armstrong AW, editors. Principles of Pharmacology: The Pathophysiologic Basis of Drug Therapy. $2^{\text {nd }}$ ed. Philadelphia (PA): Lippincott Williams and Wilkins. 2008:640-6.

3. Jagtap AG, Shirke SS, Phadke AS. Effect of polyhedral formulation on experimental models of inflammatory bowel diseases. J Ethnopharmacol. 2004;90(2- 
3):195-204.

4. Bennett PN, Brown MJ. Clinical Pharmacology. 9 ${ }^{\text {th }}$ Ed. New Delhi: Elsevier. 2006:645-8.

5. Hagar $\mathrm{HH}$, Medany AE, Eter EE, Arafa M. Ameliorative effect of pyrrolidine dithiocarbamate on acetic acid induced colitis in rat. Eur J Pharmacol. 2007;554(1):69-77

6. Emerit J, Pelletier S, Likforman J, Pasquier C, Thuillier A. Phase II trial ofsuperoxide dismutase (CuZn SOD) in the treatment of Crohn's disease. Free Radic Res Commun. 1991;13(2):563-9.

7. Levin KE, Pemberton JH, Phillips SF, Zinsmeister AR, Pezim ME. Role of oxygen free radicals in the etiology of pouchitis. Dis Colon Rectum. 1992;35(5):452-6.

8. Keshavarzian A, Sedghi S, Kanofsky J, et al. Excessive production of reactive oxygen metabolites by inflamed colon: Analysis by chemiluminescence probe. Gastroenterology. 1992;103(1):177-85

9. Yoshikawa T, Takahashi S, Kondo M. Possible role of free radicals in chronic inflammation in the gut. EXS. 1992;62:353-8.

10. Chang HM, But PPH. Pharmacological and Applications of Chinese Materia Medica. 1987. World Scientific: Singapore.

11. Chiou WF Chen CF Lin JJ. Mechanism of suppression of inducible nitric oxide synthase (iNOS) expression in RAW 264. 7 cells by andrographolide. Br J Pharmacol. 2000:129(8):1553-60

12. Chiou WF, Lin JJ, Chen CF. Andrographolide suppresses the expression of inducible nitric oxide synthase in macrophage and restores the vasoconstriction in rat aorta treated with lipopolysaccharide. Br J Pharmacol. 1998:125(2):32734.

13. Lin FL, Wu SJ, Lee SC, Ng LT. Antioxidant, antioedema and analgesic activities of Andrographis paniculata extracts and their active constituent andrographolide. Phytotherapy Research Phytother. Res. 2009:23(7):958-64

14. Goswami DV, Patil MJ, Modi A, Tiwari R. Pharmacognostic and Phytochemica investigation of stem bark of Tectona grandis Linn. Ind J of Pharm and Bio sci.
2010:1(2):1.

15. Trease GE. MC Evans, Textbook of Pharmacognosy, $12^{\text {th }}$ ed., Balliere, Tindall, London. 1983:57-9.

16. Kokate CK. Practical Pharmacognosy, $4^{\text {th }}$ ed., New Delhi: Vallabh Prakashan 1994:330- 6.

17. Khandelwal KR. Practical Pharmacognosy Techniques and Experiments. $2^{\text {nd }}$ ed. Pune, Nirali Prakashan. 2008:26-9.

18. Krawisz JE, Sharon P, Stenson WF. Quantitative assay for acute intestinal inflammation based on myeloperoxidase activity. Assessment of inflammation in rat and hamster models. Gastroenterology. 1984;87(6):1344-50.

19. Jagtap AG, Shirke SS, Phadke AS. Effect of polyhedral formulation on experimental models of inflammatory bowel diseases. J Ethnopharmacol. 2004:90(2 3):195-204.

20. Krishna MS, Nair JA. Anti-bacterial, Cytotoxic and anti-oxidant potentials from different extracts of leaves, barks and wood of Tectona grandis. Int j Pharma Sci Drug Res. 2010;2(2):155-8.

21. Kruidenier L, Kuiper I, Lamers C, Verspaget HW. Intestinal oxidative damage in inflammatory bowel disease: Semi-quantification, localization, and association with mucosal antioxidants. The Journal of Pathology. 2003;201(1):28-36

22. Abdo R, Jurjusa, Naim N, Khourya, Jean-Marie Reimundb. Appraisal of state-ofthe art Animal models of inflammatory bowel disease. Journal of Pharmacological and Toxicological Methods. 2004;50:81-92.

23. Sartor RB. Pathogenesis and immune mechanisms of chronic inflammatory bowel disease. The American J Gastroenterol. 1997;92:5S-11S

24. Akgun E, Caliskan C, Celik HA, Ozutemiz AO, Tuncyurek M, Aydin HH. Effects of $\mathrm{N}$-acetylcysteine treatment on oxidative stress in acetic acidinduced experimental colitis in rats. Inter J Medical Research. 2005;33(2):196-206.

25. Kruidenier L, Kuiper I, Lamers C, Verspaget HW. Intestinal oxidative damage in inflammatory bowel disease: Semi-quantification, localization, and association with mucosal antioxidants. The Journal of Pathology. 2003:201(1):28-36.

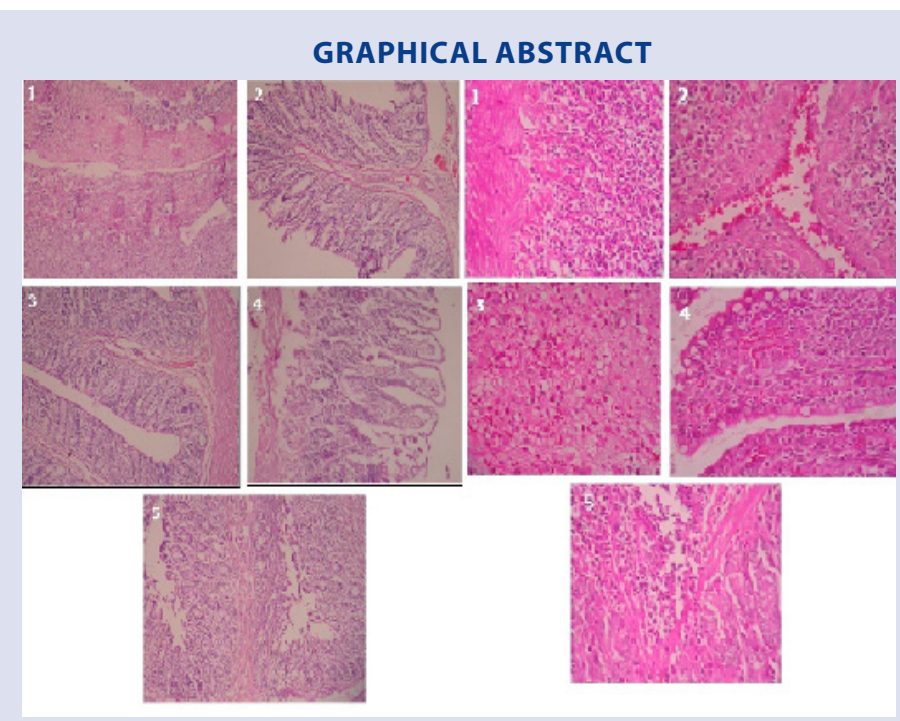

\section{SUMMARY}

- The bark extract Tectona grandis Linn. was found comparable with standard drug. The role of oxygen-derived free radicals, such as hydroxyl radical and superoxide radical, in the inflammatory process is well known. It is also generally assumed that most of the antioxidants possess anti-inflammatory effect.

- The extract of Kariyat has potent protection against inflammatory bowel activity in both indomethacin induced enter colitis and acetic acid induced ulcerative colitis. Collectively, these findings indicate that the anti-oxidant effect of fraction may be an important contributor to its anti-inflammatory activity in IBD.

\section{ABOUT AUTHORS}

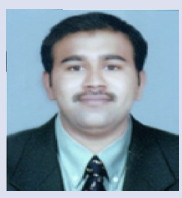

Nilesh Balasaheb Chougule, Principal, Annasaheb Dange College of D. Pharmacy, Ashta, Sangli, Maharashtra, INDIA.

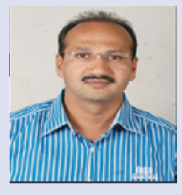

Sachin Annasheb Nitave, Principal, Anil Alias Pintu Magdum College of D. Pharmacy, Dharnggutti, Kolhapur, Maharashtra, INDIA.

Kailasam Koumaravelou, Deptartment of Centre for Research and Development, PRIST University, Vallam, Thanjavur 613 403, Tamil Nadu, INDIA

Cite this article: Chougule NB, Nitve SA, Koumaravelou K. Phytochemical Investigation and Screening for Inflammatory Bowel Disease Activity of Ethanolic Extract of Kariyat. Pharmacog J. 2018;10(3):602-10. 